\title{
DOM QUIXOTE, UMA AVENTURA CRÍTICA (E APOLOGÉTICA)
}

\author{
Luís Garcia Soto* \\ Universidade de Santiago de Compostela
}

\begin{abstract}
Resumo: No presente texto, queremos interpretar o Quixote de Cervantes desde o ponto de vista da filosofia moral. Para isso, faremos uso de duas categorias próprias da conceção da filosofia de Adorno: a crítica e a apologia. Em nossa opinião, na perceção da realidade de Dom Quixote há uma ideia de justiça que se enquadra num ideário que inclui alguns elementos transgressores a respeito da moral e a política do seu contexto histórico. Relacionaremos esses elementos transgressores com dois destacados contributos do pensamento ibérico moderno: o ius gentium e o casuísmo. Em nosso ver, Dom Quixote luta pela paz e o entendimento na política e pela liberdade de consciência na moral. Em aparência, ele fracassa sempre. Mas, em seus fracassos, às vezes ganha e às vezes perde. Por uma parte, vence quando luta contra um fato: ele erra na perceção e age de conformidade com o seu erro, mas, ao fazer isso, mostra que uma mudança é possível num dado estado de fatos moral e/ou político. A derrota de Dom Quixote implica uma crítica: ele atacou a construção social da realidade sustida e mantida pelos poderes do seu tempo. Por outra parte, Dom Quixote perde quando luta com um ídolo teatral: ele erra também, não se dá conta de que está perante uma criação dos poderes vigentes. Nestes casos, as suas derrotas significam uma dupla vitória dos poderes do seu tempo: na ordem dos fatos e na ordem das crenças. Porém, mesmo nestes casos, é possível desconstruir essa apologia. Graças ao humor de Cervantes, as/os leitoras/es podem desconstruir essa apologia e ver crítica nas aventuras de Dom Quixote.
\end{abstract}

Palavras-chave: Dom Quixote. Crítica. Moral. Política. Filosofia.

\section{Errar}

Na sua segunda saída, a primeira com Sancho, Dom Quixote ${ }^{1}$ encontra uns moinhos e vê gigantes (CERVANTES, 1994, p. 154-156). Não percebe que se trata de moinhos, e toma

Esta obra está licenciada sob uma Creative Commons - Atribuição 4.0

\footnotetext{
* Professor Titular de Filosofia Moral na Faculdade de Filosofia da Universidade de Santiago de Compostela (USC), Espanha. Licenciado em Direito (USC, 1978) e em Filosofia (USC, 1979). Doutor em Filosofia (USC, 1986) e doutor em Direito (Universidad Autónoma de Madrid, 2010). Redator do Código Ético da USC. Livros: Outramente Barthes (Nova Renascença, Porto, 1988); Paz, guerra y violencia (Espiral Maior, A Corunha, 2006); O espírito da letra. Nove achegas filosóficas a textos literários (Espiral Maior, A Corunha, 2009); Teoría de la justicia e idea del derecho en Aristóteles, (Marcial Pons, Madrid-Barcelona-Buenos Aires, 2011); O labirinto da saudade (Laiovento, Santiago de Compostela, 2012); Meditação sobre a Saudade (Zéfiro, Sintra, 2015); Barthes filósofo (Galaxia, Vigo, 2015). E-mail: luisg.soto@usc.es.

${ }^{1}$ Para os nomes em português, utilizo a tradução de Francisco Lopes de Azevedo Velho de Fonseca Barbosa Pinheiro Pereira e Sá Coelho, Conde de Azevedo, e de Antônio Feliciano de Castilho, Visconde de Castilho (CERVANTES, 2012?, p. 2).
} 
um deles por um gigante como Briareu, que ataca. O resultado: bate contra o moinho, é repelido pelas suas aspas. Mas, para Dom Quixote, o que aconteceu é que ele foi derrotado por um gigante. É este esquema, com algumas mudanças significativas, que vamos encontrar nas aventuras, nas três saídas² ${ }^{2}$ do cavaleiro chamado da Triste Figura (CERVANTES, 1994, p. 255) e depois cavaleiro dos Leões (CERVANTES, 1994, p. 749). A primeira saída é muito breve, apenas uns dias, vai ele só pelas redondezas da sua terra, um lugar da Mancha. Na segunda, viaja já com Sancho Pança como escudeiro, em direção ao sul e durante varias semanas. Estas duas saídas ocupam a chamada primeira parte d'O Quixote. A terceira saída, de longa duração, é a matéria principal da segunda parte d'O Quixote: depois de diversas peripécias, chega, com Sancho, até Barcelona.

No episódio dos moinhos, achamos o esquema do pensamento e a atuação de Dom Quixote. Primeiro: erro na perceção, devido a ele projetar sobre a realidade ${ }^{3}$ fantasias procedentes de romances de cavalaria (CERVANTES, 1994, p. 155). Segundo: intervenção na realidade, conforme a essa perceção imaginária e a um ideário também procedente da literatura de cavalaria. O centro desse ideário seria um ideal de justiça. Por último, terceiro: explicação do resultado, do acontecido, a partir dessa perceção imaginária e do ideário andantesco (CERVANTES, 1994, p. 156).

Este esquema, este mecanismo de pensamento e atuação, integra loucura e cordura: Dom Quixote é louco, é tolo, mas há também sensatez na sua tolice. É algo reconhecido, e admirado, pelos personagens que com ele topam. Ele é motivo de riso e escárnio, mas também de admiração pelo seu bom senso. As suas amostras de inteligência e prudência levantam dúvidas nos outros, no próprio Sancho e em geral, acerca de se ele efetivamente é louco. É uma questão de interpretação. Pela nossa parte, ficaremos com que Dom Quixote é doido, mas a sua loucura não exclui alguma lucidez ${ }^{4}$.

Pelo excesso de leitura e de insônia, ele chega a entender o real, e atuar nele, a partir do que leu nos romances de cavalaria. Torna-se um cavaleiro andante, vê o mundo e age como tal cavaleiro. Reparemos, nesta loucura, dois desvios: interpretar a realidade e agir segundo a literatura andantesca, e não segundo "o livro" (ou seja, a Bíblia, os Evangelhos, etc.); interpretar e aplicar essa literatura andantesca segundo o seu próprio critério (ou seja,

\footnotetext{
${ }^{2}$ Três saídas: cf. Riquer, "Índice” (CERVANTES, 1994, p. 1169-1171).

3 Realidade: entendo, e entenderei a seguir, a realidade como uma "construção social" (BERGER; LUCKMANN, 2001, p. 13-15, 36-52).

${ }^{4}$ Cf. “La locura de Don Quijote”: Riquer, “Introducción” (CERVANTES, 1994, p. 32-47).
} 
cabe dizer, segundo o "livre exame") ${ }^{5}$. Ambos os desvios são admissíveis, para o público, porque se trata de uma loucura: Dom Quixote é um doido, ambas as transgressões são inconscientes e involuntárias. Contudo, o cavaleiro encena-as, mostra a sua possibilidade, para os outros personagens e, além destes, para os leitores. E essa possibilidade, uma boa parte das vezes, não acaba imediatamente ou totalmente no fracasso. A perceção imaginária revela-se falsa, e hilariante para espectadores e leitores, mas a atuação subsequente do cavaleiro parece, por vezes e em parte, justa.

Volto ao episódio dos moinhos. Estes são para Sancho, os espectadores e os leitores, moinhos: não há gigantes, senão na visão e a mente doentes de Dom Quixote. A sua intervenção subsequente não tem consequências sobre a realidade. Como muito, alguns estragos nos objetos e algumas lesões no sujeito. Não há um ato de justiça.

Mas não acontece sempre assim: outras vezes, Dom Quixote não lida com objetos, mas com sujeitos humanos. Irrompe em cursos de ação: interrompe-os, modifica-os. Em vez de contra objetos, como os moinhos, ou contra animais, como rebanhos, Dom Quixote acomete contra sujeitos humanos: passantes, viageiros, uma comitiva ${ }^{6}$, um enterro ${ }^{7}$, uma procissão de penitentes ${ }^{8}$, uma condução de $\operatorname{presos}^{9}$. Nesses casos, na sua intervenção há uma pretensão de justiça, que pode parecer - e costuma parecer - razoável a espectadores e leitores. Pelo menos, algo razoável, capaz de abalar as suas conceções e, designadamente, a conceção partilhada por espectadores e leitores conterrâneos e contemporâneos. Ora, esta conceção e as convicções que ocasionalmente pode alicerçar não têm outro baseamento que o princípio de autoridade. Que pode resultar afetado e até substituído pela autoridade de Dom Quixote.

Mas devemos anotar também outra coisa: nesses casos, há também outra perturbação: na perceção, pois a realidade não é tão nítida como no episódio dos moinhos (e outros similares). A perceção dessas situações (passantes, viageiros, comitiva, enterro, procissão, condução, etc.) depende das ideias dos espectadores e leitores, designadamente dos seus ideários e ideais de justiça, porque essas situações envolvem, supõem e implicam, organização e regulamentação de comportamentos humanos ${ }^{10}$. Caso paradigmático é a cadeia

\footnotetext{
${ }^{5}$ Em Sade, Fourier, Loyola, Barthes exemplifica este movimento, a transmigração do texto na vida, com Dom Quixote (BARTHES, 2002, p. 704-705).

${ }^{6}$ Os frades e a senhora biscainha (CERVANTES, 1994, p. 159-163 e 169-171).

${ }^{7}$ Uns homens a trasladar um morto (CERVANTES, 1994, p. 251-255).

${ }^{8}$ Uma procissão de disciplinantes (CERVANTES, 1994, p. 600-603).

${ }^{9}$ Uma cadeia de galeotes, presos condenados a galés (CERVANTES, 1994, p. 283-294).

${ }^{10}$ Cf. "A sociedade como realidade objetiva", a sua institucionalização e legitimação (BERGER; LUCKMANN, 2001, p. 66-163)
} 
de presos, homens julgados e condenados pela justiça que, no entanto, Dom Quixote liberta (CERVANTES, 1994, p. 283-294). Mas também está envolvida, além de uma conceção do bem e do mal, uma ideia da justiça nos outros episódios, nomeadamente, o cortejo fúnebre (CERVANTES, 1994, p. 251-255) e a procissão de penitentes (CERVANTES, 1994, p. 600603). Nesses episódios, pois, a realidade não é tão segura, tão certa, como no episódio dos moinhos. Mas, atenção, reparemos que aquilo que neste episódio é - ou, melhor dito, representa - a realidade, os moinhos, são construções. Alguém fez os moinhos, poderia não os ter construído ou ter erigido alguma outra construção. Contudo, não há agentes, mas nos outros episódios há agentes: Dom Quixote intervém numa práxis, nuns relacionamentos entre sujeitos que implicam moral e política.

\section{Ideário}

Em relação com a sua época, o ideário de Dom Quixote contém elementos retrógrados, conservadores e inovadores (VILAR, 1975, p. 59-60). Por exemplo, é inovador e moderno querer aplicar os livros segundo a própria inteleção, mas é, não conservador, senão mesmo retrógrado, querer aplicar as leis da cavalaria andante. Isto significa a assunção de uma conceção feudal. Mas, há também outros elementos inovadores.

Em termos gerais, o ideário quixotesco é conforme com a ortodoxia vigente. Dom Quixote professa o militarismo ${ }^{11}$, sustém a primazia "das armas sobre as letras", com o matiz de que a função das armas é estabelecer e manter “a paz” (CERVANTES, 1994, p. 474-478, 475). Nisto, afasta-se do imperialismo, ainda que possa servir-lhe de cobertura, ao justificar a intervenção violenta. De fato, a práxis de Dom Quixote não é nem dominadora nem predatória: usa a violência para fazer justiça, sem subjugar os outros e sem obter nada para si.

Ora, esta violência desinteressada, nem dominadora nem predatória, pode servir como justificação, como álibi ideológico, de ações dominadoras e predatórias. Assim acontece com as ações do próprio cavaleiro da Triste Figura, que Sancho, em mais de uma ocasião, aproveita para tentar obter, e às vezes obter, um botim dos vencidos. Inclusivamente, toda a ação de Sancho está presidida pela intenção de obter benefício da conduta desinteressada do cavaleiro. E em mais de uma ocasião a atuação de ambos é a de uma parelha de delinquentes, que agridem e roubam outros ${ }^{12}$. Exatamente, Dom Quixote agride em nome da justiça e Sancho rouba os pertences dos derrotados pelo cavaleiro. Ambos vivem dos

\footnotetext{
${ }^{11}$ Quanto às noções de paz, de guerra e de violência, seguirei: Soto, 2006.

${ }^{12}$ Pela libertação dos galeotes, chegam a ser perseguidos e detidos pela Santa Irmandade (CERVANTES, 1994, p. 295-296, 384, 550-562, 654). Mas, para Sancho, o temor a estar fora da lei começa antes e cedo (CERVANTES, 1994, p. 173).
} 
recursos deste, mas Sancho complementa esses recursos com os botins dessas tropelias.

O cavaleiro e o seu escudeiro representam um proceder, individual e grupal, que é análogo ao imperialismo, praticado à escala social pelos estados. Condize bem com a política levada a feito pela Espanha da época, tanto em América quanto em Europa. Dom Quixote fornece uma imagem à vez sublime e ridícula ${ }^{13}$ do homem espanhol, o protagonista e herói da conquista, a colonização e o império. Isto tem consequências, efeitos sobre o público. É compreensível que para uns, designadamente dentro de Espanha, sirva para encobrir a violência, a dominação e a predação dessas empresas (eis a imagem sublime). Mas, também é compreensível que, para outros, nomeadamente fora de Espanha (para aqueles que padecem a dominação ou a hegemonia espanhola), seja uma representação paródica do homem espanhol, do militar conquistador e imperialista (eis a imagem ridícula). Os primeiros sublinham o idealismo, os segundos enfatizam o desvairo. Ambas as imagens podem explicar, desde ângulos diferentes, o sucesso d'O Quixote. Dentro, o homem sublime, com o seu idealismo, reforça o poder; fora, o homem ridículo com o seu desvairo, reforça a resistência. Duas boas razões para a difusão e o sucesso do livro.

O medievalismo de Dom Quixote é bastante conforme com a complexa realidade socioeconômica da Espanha da época. Mas, contém também elementos retrógrados, regressivos com relação às estruturas e instituições então vigentes. Assim, a sua conceção da justiça tem traços que lembram o feudalismo, a jurisdição de um senhor feudal.

Primeiro, a sua justiça é, antes de mais, violência: expressa-se primeiro como violência e depois, em segundo lugar, como razão, ou seja, como direito, a razão que fornece sentido a essa violência, que a torna justa. Em suma, a justiça de Dom Quixote não é apenas assente na violência, como a do estado, senão que os próprios atos de justiça são atos de violência, arrazoados depois. Com independência do valor destes raciocínios, da possibilidade de que sejam conformes a direito, o fato é que estes raciocínios e a eventual aplicação do direito não são antes, mas sobrevém depois da aplicação da violência. O estado e as suas instituições procedem em ordem inversa: a violência é um último recurso na aplicação do direito. É certo que na época de Dom Quixote o estado é muito violento. E também a igreja. O direito é fraco e, ainda, a justiça tende a manifestar-se como violência. Mas, o progresso moral vai no sentido de redução dessa violência, da priorização e a prevalência do direito, da argumentação e as instituições jurídicas. Frente a isto, Dom Quixote opta por uma via regressiva, que pode ser considerada revolucionária: remediar a injustiça por meio da

${ }^{13}$ Cf. A comparação com Charlot (VILAR, 1975, p. 60). Também: Cervantes e Charlot (DE LA VEGA, 1983, p. 81-90 e 91-93).

Anu. Lit., Florianópolis, v. 22, n. 1, p. 55-71, 2017. ISSNe 2175-7917 
violência, uma violência tida por justa.

Anotemos outro aspecto regressivo: pessoa frente instituição. Para Dom Quixote, a justiça está ligada à expressão de uma vontade pessoal: a sua e, em geral, a dos cavaleiros andantes. Não são instituições, mas pessoas as que fazem justiça. É certo que o direito da época é muito assim: a lei é a expressão da vontade do soberano e este é, fundamentalmente, pessoal. Contudo, a lei, essa vontade pessoal soberana, espalha-se e realiza-se através de instituições. De alguma maneira, estas, as instituições, transformam aquela, a vontade soberana, no sentido de despersonalizá-la, retirar-lhe subjetividade e fornecer-lhe objetividade. Com certeza, isto é muito pouco então, no estado e a igreja espanhóis (e europeus também). Mas, o progresso moral vai no sentido da institucionalização, da organização e o funcionamento do estado em termos de direito. Dom Quixote vai no sentido contrário: pôr em dúvida o poder estatal (e eclesial), retirar-lhe jurisdição e devolvê-la aos cavaleiros. Obviamente, a sua ação pode ser vista como revolucionária: contra um estado injusto. Nesta perspectiva, Dom Quixote combate o absolutismo e o despotismo do estado e a igreja (a ele associada).

Mas, as lutas revolucionárias podem, e devem, ser avaliadas: não são boas (ou más) per se. A revolução pode, e costuma, substituir algo mau por algo pior. Sem entrar nestas questões, salientemos que na justiça quixotesca, apesar de violenta e pessoal, há também elementos positivos, progressivos.

\section{Modernidade}

Além da compreensão livresca, o livre exame e a aplicação dos livros à realidade, há outros componentes modernos no ideário quixotesco, nomeadamente na sua ideia de justiça. Podemos relacioná-los com o que se tem chamado de "modernidade do sul" (THIEBAUT, 1989) ${ }^{14}$, que se deu na península ibérica antes do que na Europa, mas que depois se frustrou ou, sendo mais positivos, diremos que frutificou só em parte. Estamos a pensar em dois contributos peninsulares não devidamente reconhecidos: o ius gentium e o casuísmo. Este último, nada reconhecido. No entanto, o ius gentium sim foi incorporado, pelo menos parcialmente, na prática política e jurídica espanhola (FERNÁNDEZ HERRERO, 1992, p. 111-236).

A conexão com o ius gentium, e a influência deste, vemo-la na finalidade da empresa

\footnotetext{
14 Ou também "primeira modernidade" (SANTOS, 2012, p. 52-53). A sua pegada vai além do momento: "Optimismo trágico e transgressivo da subjectividade da Nuestra América" (SANTOS, 2010, p. 191-199).
} 
militar: a paz ${ }^{15}$. Ora, esta, para Dom Quixote, está no fim e também no meio. A paz não é apenas uma finalidade, está também nos meios empregados, designadamente a violência. Mas, lembremos, a violência quixotesca exclui a morte. O nosso cavaleiro usa a violência para fazer justiça, mas não mata. Há nas suas ações justiceiras um respeito pela vida das pessoas. E, por outra parte, as aventuras do cavaleiro e o seu escudeiro são uma amostra e uma posta em valor da hospitalidade: a circulação livre e segura das pessoas, de acolhimento e reciprocidade entre elas ${ }^{16}$. No ideário quixotesco há um respeito pelas pessoas, tomadas individualmente e também coletivamente. Achamos esse traço na consideração que lhe merecem as línguas e povos espanhóis e, de outra maneira, na sua atitude perante o mundo árabe.

Quanto às línguas espanholas, o outro interior ${ }^{17}$, o engenhoso fidalgo defende a coexistência pacífica e o entendimento entre as gentes, respeitando e valorizando que cada coletividade fale a sua própria língua (CERVANTES, 1994, p. 740) ${ }^{18}$. Isto é sublinhado na segunda parte d'O Quixote, pondo de parte os vários "encontros" violentos com membros dessas nações hispânicas. Mas, essas contendas, por exemplo: com os galegos, não são devidas à diversidade nacional, mas a outros fatores, nesse caso, à lubricidade de Rocinante (CERVANTES, 1994, p. 213-217). Por outra parte, os mouros representam o outro absoluto, com que se está em guerra. O cavaleiro da Triste Figura e dos Leões conhece apenas os ecos dessa realidade, pela história do cativo na primeira parte (CERVANTES, 1994, p. 480-519) e pela expulsão dos mouriscos na segunda parte (CERVANTES, 1994, p. 1023-1030) ${ }^{19}$. Registra-se, de uma a outra parte, uma mudança de atitude: de proclive ao entendimento a consentânea com a expulsão e a demonização dos mouriscos. Fundamentalmente, é uma mudança no romance, em Cervantes.

Contudo, devemos matizar esta mudança: lembremos que Cervantes atribui a autoria do seu romance a um autor árabe, Cid Hamete Benengeli, que ele traduz (CERVANTES, 1994, p. 167-170). Este detalhe é um fator de importância a favor do respeito e o entendimento: implica que essas culturas antagônicas, muçulmana e cristã, são traduzíveis. A mudança, entre a primeira e a segunda parte do romance, afeta à consideração das pessoas. Na história do cativo, apesar do fundo da guerra, há um reconhecimento da diferença e da

\footnotetext{
${ }^{15} \mathrm{Cf}$. A escola ibérica da paz (MANDADO GUTIÉRREZ; CALAFATE, 2014).

${ }^{16}$ Marinas fala de "ética do nômade" (MARINAS, 2005, p. 71-84).

${ }^{17}$ I.e., Espanha. Rodríguez Rial situa nas Meditaciones del Quijote o diagnóstico dos problemas nacionais e a terapia do "problema de Espanha” de Ortega y Gasset (RODRÍGUEZ RIAL, 2005).

${ }^{18}$ É também significativo o episódio dos bandoleiros (CERVANTES, 1994, p. 1069-1079).

${ }^{19}$ Também: a história de Ana Félix (CERVANTES, 1994, p. 1100-1104 e 1112-1114).
} 
permeabilidade entre ambos os contrários. O traço separador é a fé: e registram-se mudanças de um lado para outro. Obviamente, aplaude-se o abandono do islamismo para abraçar o cristianismo. É o caso notável de Zoraida (CERVANTES, 1994, p. 473, 496-499, 523-525, 563). As pessoas podem transitar, segundo a sua consciência, de um lado para outro, aplaudindo-se a conversão ao cristianismo (e desde este ponto de vista é condenado o processo inverso). Saliente-se agora que, na segunda parte, essa possibilidade de conversão é negada, como acontece com os mouriscos a escala coletiva, mas também no nível individual. Ora, nesse contexto de demonização absoluta, Dom Quixote e Sancho querem abrir alguma exceção e pugnam para que seja admitida a conversão de alguns (CERVANTES, 1994, p. 1112-1114).

Por outra parte, temos o casuísmo, também denominado probabilismo e, criticamente, laxismo (ALMEIDA, 1994, p. 18-29). Probabilismo, porque numa ação e situação concretas admite seguir uma opinião provável, sendo inclusive contrária ao critério moral geral. E laxismo, porque implica uma relaxação da norma em benefício da consciência. Tem sido alcunhado, depreciativamente, como "jesuitismo", por ter sido desenvolvido por jesuítas (ALMEIDA, 1994, p. 31-44). Não gozou de fortuna histórica, não conseguiu integrarse na moral e persistir, ou só muito minimamente ${ }^{20}$. Mas, achamos traços do casuísmo no proceder do cavaleiro da Triste Figura e dos Leões: não apenas na adaptação da norma ao caso concreto, que ele faz com muitos matizes, mas, sobretudo, na prevalência e o valor outorgados à consciência e a decisão consentânea individual (MARINAS, 2005, p. 51-68).

Vemo-lo, por exemplo e em primeiro lugar, na questão matrimonial ${ }^{21}$. Dom Quixote defende reiteradamente que o matrimônio deve fazer-se pela vontade consciente e livre das partes contraentes: as pessoas que casam. E essa vontade, esse consentimento, deve estar assente no sentimento mútuo. O nosso cavaleiro desafia as normas e/ou os costumes que entendem o casamento como aliança ou negócio entre famílias. Opõe-se, pois, antes de mais, aos próprios critérios andantescos, feudais, ainda vigorosos na sua época. $\mathrm{Na}$ sua ótica, o casamento é assunto do indivíduo e deve ser o resultado de um ato de vontade consciente e livre, por ambas as partes, o homem e a mulher. É importante sublinhar que Dom Quixote salienta e ressalta a liberdade, também, da mulher. A sua decisão, em igualdade com a do homem, é constitutiva para o casamento. Que ela pode recusar, sem que por isso deva optar

\footnotetext{
${ }^{20} \mathrm{Na}$ atualidade, o casuísmo foi recuperado na bioética, a partir da reivindicação levada a feito por Jonsen e Toulmin (JONSEN, 2016, p. 4). Neste artigo, Jonsen lembra alguns dos fundadores e figuras da casuística e o probabilismo clássicos: Azpilcueta, Azor, Escobar y Mendoza (JONSEN, 2016, p. 3).

${ }^{21}$ Por exemplo, e como paradigma, a história de Basílio e Quitéria (CERVANTES, 1994, p. 761-785). O episódio central é "as bodas de Camacho".
} 
pelo convento.

Este segundo aspecto é ainda mais notável e rubrica o valor da expressão da vontade individual, neste caso na mulher que é um sujeito socialmente diminuído. Dom Quixote salienta, contra a opinião comum, a liberdade da mulher a respeito do homem ${ }^{22}$. Designadamente, argumenta que uma mulher pode mostrar os seus talentos, a sua beleza e o seu engenho, sem por isso contrair responsabilidade alguma com aquele ou aqueles que eventualmente a admirem. Por outras palavras, não está obrigada a responder os requerimentos amorosos, não tem nenhuma responsabilidade pelas coitas de amor que ela, devido à sua beleza e/ou ao seu talento, ocasione. Inclusivamente, assinala o cavaleiro, uma mulher pode exibir essa beleza e/ou esse talento e, depois, fica tão livre como dantes. Ela tem o direito pleno a ignorar ou rejeitar o pretendente: os sofrimentos amorosos (e os eventuais trabalhos subsequentes) podem ser um argumento dele, mas não comprometem nada a liberdade dela. É muito importante, e singular, esta defesa da liberdade individual, mais porque se trata da mulher, marginalizada socialmente a respeito do homem (BEAUVOIR, 1962, p. 139-146).

O engenhoso fidalgo, no entanto, quase não tem relação com mulheres qua mulheres. Quer dizer, relaciona-se com elas como indivíduos, mas não como mulheres. Há algumas tentativas por parte de algumas, mas não frutificam. Talvez porque o lugar da mulher é ocupado por Dulcinéia. Contudo, a mulher que chega a ter mais relação com ele é Altisidora, que finge estar interessada nele, mas com a intenção de burlar-se dele e de humilhá-lo (CERVANTES, 1994, p. 948-951, 959-961, 963). Não consegue (CERVANTES, 1994, p. 1043-1046 e 1130-1142). Mas não é porque Dom Quixote resista: parece não dar-se conta do seu fingimento: não registra o afeto dela nos termos próprios de uma relação amorosa. Que também não há com Dulcinéia.

Dulcinéia, em nossa opinião, é mais uma função do que uma pessoa. Dulcinéia constitui, para Dom Quixote, a principal razão de ser para as suas andanças. Mas, é uma simples referência, uma exigência da cavalaria: ela é a dama que deve nortear as ações do cavaleiro (CERVANTES, 1994, p. 106).

\section{Crítica $^{23}$}

Em resumo, Dom Quixote bate com o real de duas maneiras: com a sua perceção e

\footnotetext{
${ }^{22}$ É paradigmática a história de Marcela (CERVANTES, 1994, p. 185-192 e 200-211).

${ }^{23}$ Emprego, e empregarei a seguir, "crítica" no sentido de Adorno, que, em 1962, em seu texto "Para que, ainda, filosofia?", defende a tarefa atual da filosofia como labor "crítico", e rejeita qualquer função "apologética" (ADORNO, 2009, p. 401-414).
} 
com a sua intervenção. Da primeira, segue a segunda. Ambas podem ser atribuídas à loucura, mas, segundo temos examinado, é uma loucura que contém também sensatez. Mas essa sensatez é algo mais do que bom senso: é uma inteligência prática que ultrapassa a conceção habitual dos conterrâneos e contemporâneos, sejam os espectadores coprotagonistas sejam os leitores possíveis das aventuras do engenhoso fidalgo. No seu ideário, centrado na justiça, há traços conformes, traços retrógrados e traços críticos com as normas e os usos sociopolíticos vigentes. E, com independência de ele ser louco, os espectadores, e possivelmente os leitores, apreciam o valor do seu critério. Ou seja, atribuem-lhe um valor objetivo, separando-o do sujeito, não cordato, que o sustenta. É como se ele acertasse por casualidade ou porque, no fundo, não é doido. Estas dúvidas, será ele sábio?, surgem com as suas intervenções. A sua tolice parece como um meio, um caminho, um percurso, um túnel, uma passagem pela escuridão para atingir as luzes: para chegar à cordura, à sensatez, o bom senso, o juízo justo. Afinal, então, inverte-se o processo: a intervenção quixotesca justa valida a perceção imaginária andantesca.

Em suma, Dom Quixote é duas vezes, duplamente, crítico com o real. Primeiro, porque fornece critérios novos e resolve segundo eles, afastando-se das normas, usos e poderes vigentes. E, segundo, porque esses critérios aparecem dotados de um valor objetivo, ao serem independentes e alheios à loucura do sujeito. O primeiro implica enfrentar-se com o real, pôr em dúvida que deva ser tal como é, justificar o desvio, fornecer inovações, etc. Dom Quixote introduz um potencial crítico, uma quebra no real, capaz de afetar a espectadores e leitores nas suas conceções e convicções. Esta susceptibilidade deriva também do fato de serem espectadores e leitores mormente iletrados e crédulos: isto é, habituados a crerem o que dizem as autoridades. Isto leva-nos à segunda perturbação introduzida pelo nosso cavaleiro: a possível objetividade dum juízo, o valor objetivo de um critério. Isto também supõe um enfrentar-se com o real, porque os critérios vigentes descansam na autoridade dos sujeitos, estado e igreja, que os enunciam e os súbditos assumem como a mesma realidade. O real, a verdade que o estabelece e a justiça que o regulariza são a expressão da vontade dessas autoridades. Podemos simplificar dizendo que o real da realidade é o real da realeza, o que estado e igreja estabelecem. E Dom Quixote bate com o real e luta contra o real.

\section{Errar, de novo}

Ora bem, da primeira à segunda parte d'O Quixote muda a perspectiva e a compreensão que os espectadores e os leitores podem ter acerca das aventuras do cavaleiro. $\mathrm{Na}$ primeira parte, a focagem sobre o personagem e o narrado no romance permitem a 
aparição e formação de uma visão crítica. O cavaleiro da Triste Figura habilita uma perspectiva e uma atitude críticas em relação com o real. Não acontece o mesmo com o cavaleiro dos Leões, que é como aquele passa a denominar-se na segunda parte. A focagem sobre o personagem e o narrado no romance não habilita uma visão crítica: fornece uma perspectiva e uma compreensão apologéticas ${ }^{24}$ do real. Acontece que as aventuras do engenhoso fidalgo, com algumas exceções, mudam substancialmente. O ponto de partida, o desenvolvimento e o desenlace são diferentes. Por outras palavras, a perceção imaginária e a intervenção justiceira quixotescas mudam significativamente: ambas dão-se no plano da ficção.

Nas aventuras do cavaleiro da Triste Figura o ponto de partida é um erro percetivo: Dom Quixote interpreta mal, conforme aos romances de cavalaria, um fato ou um evento da vida quotidiana. A seguir, atua em consequência, isto é, conforme à situação percebida e a sua interpretação pessoal a partir dos livros de cavalaria. Ora, nessa atuação, inova: introduz critérios e ações com traços diferentes aos vigentes (muitos críticos) ${ }^{25}$. A sua intervenção é expressão de liberdade e de justiça. O público, espectadores e leitores, desfruta com a perceção imaginária quixotesca, mas também com a sua intervenção, com essa inovação que reporta liberdade e justiça. Eis o potencial crítico, embrulhado em humor, que erode, corrói e até derrui o real. Até ao ponto de tornar pensável uma realidade diferente, mesmo alternativa. Porque, como salientamos, a intervenção justiceira quixotesca valida a perceção imaginária andantesca. Atenção: não é que a torne verdadeira, mostra o potencial criador do sujeito. Por exemplo, não valida o erro de que os moinhos são gigantes: mostra que o sujeito pode construir realidade, nem sempre errada. A práxis quixotesca salienta as virtualidades da episteme (a ciência, o conhecimento) quixotesca, incluindo o recurso à téchne (a técnica, a produção $)^{26}$.

Não acontece o mesmo na segunda parte d'O Quixote. O ponto de partida das aventuras do cavaleiro dos Leões é também um erro na perceção. Mas, ele não interpreta mal um acontecimento senão um fingimento. $\mathrm{O}$ engenhoso fidalgo toma por real o que é uma representação. Cai no engano, fica nele e não sai dele: atua em consequência, seguindo os

\footnotetext{
${ }^{24}$ Também, como antes "crítica", no sentido de Adorno. "Crítica" ou "Apologética": eis a disjunção que apresenta Adorno na sua meditação acerca da tarefa atual e possível da filosofia (ADORNO, 2009, p. 401-414).

${ }^{25}$ López Pérez salienta o aspecto transgressor, que segundo ele motiva a versão de Dom Quixote e Sancho Pança normalizados, um louco num manicômio e um bufão na corte, que se acham no Quixote de Avellaneda, publicado em 1614 (CERVANTES, 2004, p. 17). Em sua opinião, Cervantes na segunda parte, publicada em 1615, reincide no seu "modelo transgressor" (CERVANTES, 2004, p. 17). De fato, poderíamos ler essa segunda parte como uma "arte da escrita" para escapar à "persecução" (STRAUSS, 1996, p. 57-92).

${ }^{26}$ Práxis, episteme, téchne: no sentido de Aristóteles. Cf. SOTO, 2011, p. 295-310.
} 
seus parâmetros quixotescos, e, com isso, confirma o engano. Em suma, mostra a não validade da sua mundividência, tanto no seu aspecto teórico, de inteleção da realidade, como no seu aspecto prático, de intervenção na realidade. De fato, ele não intervém na realidade: inconsciente e também néscio, interpreta um papel numa representação teatral. É o que acontece em episódios como os do cavalo Clavilenho (CERVANTES, 1994, p. 916-931) e os diversos celebrados sob a hospitalidade do Duque (CERVANTES, 1994, p. 849-1048 e 11291142). Estes são autênticas peças teatrais, organizadas como um espetáculo, que o engenhoso fidalgo não percebe e crê estar a intervir na realidade mesma.

\section{Apologia}

Em consequência, Dom Quixote, com a sua atuação, não inova, mas repete o seu estereótipo: confirma o seu erro percetivo e judicativo e exibe-se a si próprio, não como um sujeito, mas como um objeto, mostrando a previsibilidade e o automatismo da sua conduta. Para o público, o cavaleiro não é objeto de admiração, mas de irrisão. Espectadores e leitores podiam admirar o cavaleiro da Triste Figura pela inovação, a liberdade e a justiça que trazia com a sua atuação. Mas, o cavaleiro dos Leões simplesmente, literalmente, atua: representa um papel sem o saber, põe em cena a sua ignorância e impotência frente a fingimentos fabricados, cuja artificialidade e arbítrio são manifestos. Artificialidade e arbítrio: são fingimentos fabricados pelo poder, por pessoas que têm algum poder e, mesmo, representam os poderes socialmente vigentes. O público, então, ri de Dom Quixote e, ao mesmo tempo, rubrica a sua submissão a esses poderes. É como um combate entre a loucura e a razão, e entre a falsidade e a verdade, e entre o mal e o bem, e entre a arbitrariedade e a justiça, etc. E nesse combate Dom Quixote leva a parte do mal (a loucura, a falsidade, a arbitrariedade) e o bem (a razão, a verdade, a justiça) cai do lado do poder. Que é, de uma maneira explícita, o poder então socialmente vigente. Dom Quixote fica desqualificado, humilhado e vencido pelos poderes, estatais e eclesiais, vigentes. Que são, deste modo, continuamente louvados e enaltecidos. O público, espectador e/ou leitor, assiste a uma ininterrupta apologia do poder sociopolítico estabelecido. Os coprotagonistas do romance participam mesmo nessa apologia. É de salientar o papel, também involuntário, de Sancho.

Sancho, como dizíamos, também participa nessa apologia. Como o seu senhor, também é vitima de um fingimento: é nomeado e exerce como governador de uma ilha chamada Barataria (CERVANTES, 1994, p. 952-953). A nominação é a culminação do seu trabalho, o objetivo perseguido com o serviço ao cavaleiro. Sancho serve Dom Quixote pela retribuição e os benefícios acordados por esse serviço. O governo de uma ilha é o objetivo e a 
recompensa principais. O escudeiro é, pois, um homem do povo que tem uma conceção utilitária da prestação de serviços. $\mathrm{Na}$ sua perspectiva, não cumpre apenas esperar a retribuição de um trabalho feito, mas gozar de vantagens adicionais. Estes benefícios são a principal motivação da sua ação, do serviço que presta ao cavaleiro. Em termos semelhantes, ocupar o posto de governador será ter a ocasião de se enriquecer, entre outras formas de tirar um proveito pessoal do exercício desse poder. Além disso, ele pressupõe que não são precisos dotes especiais para fazer parte da classe política: ele próprio, como quase qualquer outro com saber popular e bom senso, está em condições de aceder a um posto de governação e de realizar uma ação de governo (CERVANTES, 1994, p. 953-959). Dizemos como "quase" qualquer outro: Sancho tem uma conceção parcialmente democrática: não defende o acesso universal ao poder, mas sim que este não é privilégio de uma classe letrada, nobiliária ou eclesiástica. Por outras palavras, ele não pensa que todos poderiam, e eventualmente deveriam, aceder ao poder. No entanto, considera que o poder não requer nem um estatuto nem uns méritos exclusivos de umas classes sociais, nomeadamente a nobreza e o clero.

A sua experiência como governador da ilha vai deitar para baixo essa expetativa de benefício e essa convicção acerca das suas capacidades (CERVANTES, 1994, p. 980-991). Governando a ilha, Sancho comprova, experimenta, que o poder não reporta benefícios, mas que exige sacrifícios. $\mathrm{O}$ poder não brinda ocasiões para o benefício, mas requer inúmeros $\mathrm{e}$ imensos sacrifícios. O governante deve sacrificar o bem próprio pelo bem alheio e é assim, seguindo essa regra, como funcionam as instituições. E, por outra parte, experimenta, comprova, que não basta com a sabedoria popular e o bom senso, que ele possui, para governar $^{27}$. Esse saber, e essa prudência, não é possível convertê-los em poder, nem em justiça. Ele vê-se impotente para resolver os assuntos que lhe apresentam. E apenas tem compensação pelo exercício do poder: a única, cedo insuficiente, é a comida. Por isso, nasce nele cedo o desejo de fugir às responsabilidades do governo e retornar à sua condição de escudeiro e simples homem do povo (CERVANTES, 1994, p. 1016-1021). O resultado da sua experiência é uma apologia do poder vigente, que fica não apenas reafirmado, mas também purificado das suspeitas (benefício, privilégio) de Sancho, que podem ser em geral as do povo.

Não esqueçamos que a experiência política de Sancho é como as aventuras do seu senhor: puro engano, puro fingimento. Não há ilha, não há governo, não há súbditos. Tudo é teatro, ação representada por atores num cenário artificial, para delícia das classes dirigentes.

\footnotetext{
${ }^{27}$ Cf. A "democracia medieval” e a "modernização do estado" (VILAR, 1975, p. $22-23$ e 39-40).
} 
E também para divertimento e escárnio do povo, que tem a possibilidade de partilhar com o poder a burla e humilhação de um popular como eles. Dom Quixote oferece o mesmo espetáculo, a mesma lição moral, protagonizada, não por um popular, mas por um letrado, um intelectual alheio às classes dirigentes. A segunda parte do romance, as novas aventuras do cavaleiro e o seu escudeiro, contém uma apologia, até ao paroxismo, do poder vigente, o poder real que é o poder da realeza, da nobreza estatal e eclesiástica. Contra esse poder soberano bate Dom Quixote e bate também Sancho, batem o louco e o cordato. E fracassam. Nem chegam a perceber a rede em que são apresados. São derrotados e rendem-se. Sem chegarem a saber que foram enganados, que seguindo as suas próprias ideias entraram num dispositivo que acaba por mostrar, ao público, o erro e a impotência dos seus ideários. Uns ideários que têm algo de subversivo, crítico o do cavaleiro, perverso, ingênua e levemente perverso, o do escudeiro.

\section{Desconstrução}

Mas, nem tudo é apologia. A desventura de Dom Quixote e Sancho constitui, com muita probabilidade, um espetáculo apologético para o público conterrâneo e contemporâneo, os espectadores e/ou os leitores. Mas, o público do romance ultrapassa esses limites de tempo e lugar. O leitor e/ou leitora que se achar em condições de liberdade poderá pensar outra coisa: pode tirar lições, não apologéticas, mas críticas $^{28}$. A primeira, que a destruição do ideário do cavaleiro mostra, mesmo na sua derrota, o seu potencial, as suas virtualidades críticas. A segunda, não menos importante, que a apologia do poder mostra o funcionamento do poder. Trata-se de um poder essencialmente tecnocrático: através da técnica, constrói realidade. O que chamamos de realidade, o que cremos real, é um teatro. O poder erige cenários, impõe argumentos, arma atores, que cumprem funções e interpretam papeis, para dirigir as ações, a vida, dos indivíduos e as gentes, para os dominar e os explorar. O real é uma construção, uma produção técnica, designadamente da realeza, que arma e dirige o grande teatro do mundo. A essa téchne, ao real da realeza, opõe Dom Quixote a sua práxis: em vão, inutilmente, mas para exemplo de outros que saberão agir outramente. Podemos ficar por aqui, com esta lição moral crítica.

Mas, brevemente, regressemos ao princípio: os moinhos, que o cavaleiro ataca, não são gigantes. Estes são uma fantasia; aqueles, a realidade. Exatamente, não são a realidade, mas uma realidade construída: uns sujeitos erigiram os moinhos, outros podem derruí-los. O

\footnotetext{
${ }^{28}$ A chave está na mesma matriz do Quixote: o humor (DE LA VEGA, 1983, p. 16-21). O humor permitiria a desconstrução da apologia e a reconstrução da crítica (DE LA VEGA, 1983, p. 51-80).
}

Anu. Lit., Florianópolis, v. 22, n. 1, p. 55-71, 2017. ISSNe 2175-7917 
realismo ingênuo não percebe este caráter factício. Não vê, no real, a construção social. O moinho, o gigante como Briareu, é também outra. Não parece sensato lançar-se contra um moinho, mas talvez seja justo combater Briareu, isto é, aquilo que este imaginário gigante possa representar. Dom Quixote aponta nessa direção, assinalando a práxis, a ação individual e a relação intersubjetiva, como base para a construção social da realidade. Essa perspectiva emancipadora apagar-se-ia se os moinhos fossem um decorado, contra o qual, igualmente, se precipitasse Dom Quixote. A práxis apareceria, então, como uma ilusão no reino da técnica. Mas, ao manifestar, em certo modo desvelar, o império da técnica seguiria a oferecer uma hipótese (ainda que mais remota) de contestação, de resistência, de subversão.

Uma última reflexão: Dom Quixote é derrotado, depois retorna à realidade. Para isso, Sansão Carrasco, um conterrâneo seu, entra na loucura do cavaleiro. Aquele é um jovem que sente afeto por Dom Quixote. Tenta animar o cavaleiro, quando este, concluída a sua segunda saída, se encontra abatido na sua casa. Até chega a propiciar que o engenhoso fidalgo retome as suas aventuras (CERVANTES, 1994, p. 656-659 e 675-678). Mas, quando estas começam, percebe o perigo que representam para o cavaleiro. Ocorre-lhe, para cortar as peripécias quixotescas, disfarçar-se de cavaleiro, desafiá-lo, derrotá-lo e obrigá-lo a voltar para a sua casa. Mas, acontece que na primeira tentativa fracassa: Sansão Carrasco, sob o nome de cavaleiro dos Espelhos reta Dom Quixote, mas, contra toda a expetativa, este resulta vencedor (CERVANTES, 1994, p. 725-730). E Sansão Carrasco, ferido, tem de regressar a aldeia. Por isso, o cavaleiro dos Leões pode prosseguir o seu périplo aventureiro muito tempo até chegar a Barcelona. Nesta cidade, reaparece Sansão Carrasco, agora cavaleiro da Branca Lua, que derrota o engenhoso fidalgo, impondo-lhe a obriga de renunciar durante um ano à vida de cavaleiro andante (CERVANTES, 1994, p. 1104-1111). Dom Quixote regressa à sua casa, ideando ainda o projeto de abraçar a vida pastoril. Mas, de volta no lar, recobra a lucidez, adoece e, ao pouco tempo, falece. A entrada do bacharel Carrasco na vida louca de Dom Quixote, para tira-lo dessa existência, mostra que, dessa loucura, é possível o retorno à realidade. E não necessariamente para morrer. Porém, esse já não é o combate de Dom Quixote, mas a interpelação que nos deixa a nós, leitoras e leitores.

\section{Referências}

ALMEIDA, Ângela Mendes de. O gosto do pecado: casamento e sexualidade nos manuais de confessores dos séculos XVI e XVII. Lisboa: Rocco, 1994.

ADORNO, Theodor W. Crítica de la cultura y sociedad II. Traducción de Jorge Navarro Pérez. Madrid: Akal, 2009. 
BARTHES, Roland. Oeuvres complètes $(I, I I, I I I, I V, V)$. 2. ed. Édition de Éric Marty. Paris: Seuil, 2002.

BEAUVOIR, Simone de. El segundo sexo: 1. Los hechos y los mitos. Traducción de Pablo Palant. Buenos Aires: Siglo Veinte, 1962.

BERGER, Peter L.; LUCKMANN, Thomas. La construcción social de la realidad. 17. ed. Traducción de Silvia Zuleta. Buenos Aires: Amorrortu, 2001.

CERVANTES, Miguel de. Don Quijote de la Mancha. Edición, introducción y notas de Martín de Riquer. Barcelona: RBA, 1994.

. Don Quijote de la Mancha. Edición, introducción y notas de José Luis Pérez López. Toledo: Empresa Pública Don Quijote 2005, 2004.

D. Quixote de la Mancha. Tradução de Francisco Lopes de Azevedo Velho de Fonseca Barbosa Pinheiro Pereira e Sá Coelho, Conde de Azevedo, e Antônio Feliciano de Castilho, Visconde de Castilho. Belém-Pará: Universidade da Amazônia, [2012?].

DE LA VEGA, Celestino F. O segredo do humor. Vigo: Galaxia, 1983.

MANDADO GUTIÉRREZ, Ramón; CALAFATE, Pedro. Escuela ibérica de la paz / Escola ibérica da paz: la conciencia crítica de la conquista y colonización de América (1511-1694). Santander: Universidad de Cantabria, 2014.

FERNÁNDEZ HERRERO, Beatriz. La utopía de América: Teoría. Leyes. Experimentos. Barcelona: Anthropos \& Madrid: Centro de Estudios Constitucionales, 1992.

JONSEN, Albert. Razonamiento casuístico en la ética médica. Dilemata, Madrid, año 8, n. 20, p. 1-14, enero de 2016.

MARINAS, José Miguel. Los nombres del Quijote: una alegoría de la ética moderna. Madrid: El Rapto de Europa, 2005.

RODRÍGUEZ RIAL, Nel. Meditaciones del Quijote de Ortega y Gasset o experimentos de "nueva España". Diacrítica, Braga, n. 19-1, p. 9-67, 2005.

SANTOS, Boaventura de Sousa. A gramática do tempo: para uma nova cultura política. 2. ed. Porto: Afrontamento, 2010.

Portugal, ensaio contra a auto-flagelação. 2. ed. Coimbra: Almedina, 2012.

SOTO, Luís G. Paz, guerra y violencia. Traducción de Tareixa Roca. A Coruña: Espiral Maior, 2006.

. Teoría de la justicia e idea del Derecho en Aristóteles. Madrid-Barcelona-Buenos Aires: Marcial Pons, 2011.

STRAUSS, Leo. Persecución y arte de escribir y otros ensayos de filosofía política. Edición de Antonio Lastra. Valencia: Alfons el Magnànim, 1996. 
THIEBAUT, Carlos. Sujeto complejo, identidad narrativa, modernidad del sur. In: CASTILLA DEL PINO, Carlos (comp.). Teoría del personaje. Madrid: Alianza, 1989, p. 121-144.

VILAR, Pierre. Historia de España. Traducción de Manuel Tuñón de Lara. Paris: Librairie Espagnole, 1975.

\section{Don Quixote, a critical (and apologetic) adventure}

Abstract: In this text, I intend to interpret Cervantes's Don Quixote from a moral point of view. I use two categories that I borrow from Adorno's conception of philosophy: criticism and apology. In my view, in Don Quixote's perception of reality there is an idea of justice that implies an ideology that includes some transgressing elements in relation with the morals and politics of his historical context. I connect these transgressing elements with two outstanding contributions of modern Iberian thought: ius gentium and casuistry. In my view, Don Quixote fights for peace and understanding in politics and for freedom of consciousness in morals. $\mathrm{He}$ wrestles with a political and moral construction of reality. Apparently, he always fails. But, in his failures, sometimes he wins and sometimes he loses. On the one hand, Don Quixote wins whenever he struggles with a fact: he misunderstands it and he reacts according with his view, but, in doing that, he shows that a change is possible in a moral and political state of facts. Don Quixote's defeat conveys a way of criticism: he launched an attack on the social construction of reality held and kept by the establishment of his time. On the other hand, Don Quixote loses when he struggles with an idol of theatre: he misunderstands it too, and he doesn't realize that it is a creation of established powers. In those cases, his defeats imply a double victory of the establishment: in the order of facts and in the order of beliefs. In these cases, Don Quixote's defeat means an apology of the establishment of his time. But, even in that case, it is possible to deconstruct this apology. By way of Cervantes' humour, readers can deconstruct this apology and see criticism in Don Quixote's adventure.

Keywords: Don Quixote. Criticism. Morals. Politics. Philosophy.

Recebido: $29 / 12 / 2016$

Aceito: $13 / 03 / 2017$

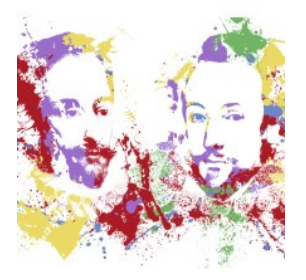

